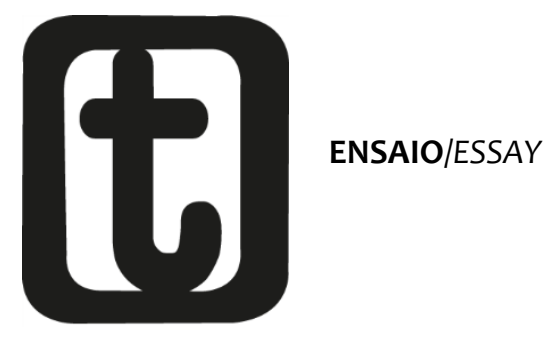

\title{
NA CONTRACORRENTE DA REFORMA DO ENSINO SUPERIOR: NÓTULA SOBRE O CURSO DE GRADUAÇÃO EM SERVIÇO SOCIAL PARA OS ASSENTADOS DA REFORMA AGRÁRIA
}

Against the mainstream reform of higher education: notes on the undergraduate program in Social Work for agrarian reform settled families

\section{Yolanda Guerra ${ }^{1}$}

Numa sociedade de classes, se a classe trabalhadora não amadurece politicamente, se não se desenvolve como classe independente, $\mathrm{o}$ intelectual que se identifica com ela não pode ser instrumental para nada. A menos que ele queira ser instrumental para as suas inquietações, para o seu nível de vida, para um trabalho pessoal criador. Mas, se você vai além disso, você se esborracha. O que aconteceu comigo foi que eu me esborrachei e daí o fato de que, até hoje, não me conformo com o nosso padrão de

\footnotetext{
${ }^{1}$ Professora da Disciplina Introdução ao Serviço Social da turma especial para assentados da Reforma Agrária, Membro da Comissão Editorial da Temporalis. Email: <yguerra1@terra.com.br>.
}

Temporalis, Brasilia (DF), ano 11, n.21, p.239-270, jan./jun. 2011. 
radicalismo e de socialismo (FLORESTAN FERNANDES, 1981).

Neste número dedicado a uma temática de extremada relevância social - Universidade, Movimentos Sociais e Serviço Social - não poderíamos deixar de expor uma experiência, talvez a mais importante em termos de formação profissional dos últimos tempos, tanto pelo seu significado político-acadêmico quanto pelos desafios que ela propõe nos âmbitos: da universidade, com suas práticas acadêmicas elitistas e de fragmentação do saber, do Serviço Social, profissão conformada por um histórico conservadorismo e, sobretudo, no da sociedade brasileira, marcada pela sua inserção subalterna na econômica mundial, brutal concentração de renda e desigualdade social e por renovadas práticas anti-democráticas.

Com este espírito e objetivo, aceitei a tarefa militante de organizar o material composto pelo relato e análise critica da proposta que está sendo desenvolvida pela Escola de Serviço Social da UFRJ seguidos dos depoimentos ${ }^{2}$ de alguns dos sujeitos que protagonizam a primeira turma de graduação em Serviço Social direcionada aos trabalhadores assentados da terra, militantes do Movimento dos Trabalhadores Rurais Sem Terra (MST) e de outros movimentos afins. Com o escasso tempo de que dispusemos para isso, e tendo em vista alguns princípios que fundamentam a proposta, todos os que aqui se pronunciaram o fizeram na perspectiva da defesa do direito ao acesso universal aos bens e serviços, dentre os quais o direito à educação universal, pública, laica, gratuita, de qualidade e socialmente relevante e do compromisso com um outro projeto de sociedade .

\footnotetext{
${ }^{2}$ Ressalto que os depoimentos me foram enviados por e-mail com a finalidade exclusiva de compor este ensaio.
} 


\section{tempordils}

GUERRA, Y. NA CONTRACORRENTE DA REFORMA

Este material foi organizado a partir da seguinte lógica: a proposta do Programa Nacional de Educação na Reforma Agrária (PRONERA) como política de capacitação no campo apresentada por Erivan Hilário, um dos coordenadores da Escola Florestan Fernandes, destacado para acompanhar diretamente a operacionalização do curso; o depoimento de Maristela Dalmoro, professora da Escola de Serviço Social da Universidade Federal do Rio de Janeiro e coordenadora do primeiro curso de graduação em Serviço Social, a que se segue o de dois professores da turma, Rogério Lustosa e Henrique Weller, das disciplinas Introdução ao Trabalho Cientifico e Teoria Política, respectivamente. Na seqüência, expressivos depoimentos dos militantes que compõe a turma deste primeiro curso de graduação para assentados militantes dos movimentos sociais. Fechando o texto, apresentamos o depoimento da profa. Claudia Monica dos Santos, presidente da Associação Brasileira de Ensino e Pesquisa em Serviço Social (ABEPSS), sobre o posicionamento da entidade acerca do rico significado da experiência.

Embora os depoimentos sejam suficientemente significativos e expressem a efetiva relevância desta experiência, penso ser importante situá-la no contexto da política do governo para o ensino superior.

Ora, os dados recentes vêm mostrando que o governo Lula realizou uma ampla e irrestrita abertura ao capital privado, como marca histórica da inserção subalterna do país aos interesses do grande capital internacional.

Dando seguimento ao que havia sido forjado pelo projeto que instaurou a ditadura militar, a proposta de reforma do ensino superior do governo Lula articula diversos interesses que vão

Temporalis, Brasilia (DF), ano 11, n.21, p.239-270, jan./jun. 2011. 
desde os da burguesia financeira, passando pelos da nova burguesia de serviços e incluindo os da burguesia industrial. Além disso, sua política educacional tem sido apoiada pelos segmentos médios e setores da classe trabalhadora e, sobretudo, conta com a adesão de organizações acadêmicas, políticas e sindicais (a este respeito Associação Nacional de Dirigentes de Instituição Federais de Ensino Superior (ANDIFES) e a União Nacional dos Estudantes (UNE) são exemplares) afetando diretamente a autonomia dos movimentos que lutam por um determinado projeto de educação.

As características essenciais desta reforma regressiva podem ser expressas em dois pontos que se relacionam intimamente: 1) a massificação degradante da educação - Programa Universidade para Todos (PROUNI) e o Programa de Apoio a Planos de Reestruturação e Expansão das Universidades Federais (Reuni) decorrente de dois processos. O primeiro, da expansão desmesurada de vagas para instaurar um modelo educacional caracterizado pela fusão entre público e privado, sob o molde e as orientações dos organismos internacionais - do qual as parcerias público-privado são expressão - o que supostamente tiraria o Brasil do atraso em relação aos demais países da América Latina, atenderia a demanda reprimida dos concluintes do ensino médio e garantiria o direito de cidadania, pela democratização do acesso, discurso dotado de um apelo populista quase que inquestionável e que vem angariando adesões de vários sujeitos políticos individuais e coletivos. A ampliação das ofertas tem um efeito profundamente ideológico, pois na sua aparente imediaticidade tratar-se-ia de uma democratização do ensino e geração de iguais possibilidades no mercado. O segundo processo, que visa contemplar interesses mercantis dos grandes conglomerados da educação, constituindo um modelo de oligopólio na educação superior privada (CHAVES,

242 Temporalis, Brasilia (DF), ano 11, n.21, p.239-270, jan./jun. 2011. 


\section{temporolis}

GUERRA, Y. NA CONTRACORRENTE DA REFORMA

2010) ${ }^{3}$, no qual a universidade é ela mesma transformada em mercado, tendo como decorrência, entre outras, o crescimento do Educação a Distância $(E A D)^{4}$, reforçando a política de tais organismos no que concerne a atribuir aos países periféricos a condição de reprodutores do conhecimento (BRASIL, 2005). Os serviços educacionais, produzidos pelas instituições de ensino superior, são vendidos no mercado como qualquer outra mercadoria. Este seria o objetivo das instituições de ensino superior em países como o Brasil, segundo o modelo do Banco Mundial. Disto decorre a crescente mercadorização, a construção do modelo de universidade operacional, que abole a pesquisa e destina-se exclusivamente ao mercado, para o que os cursos de Serviço Social, por serem relativamente baratos, caem feito uma luva. A resultante é a criação de um mercado educacional, focalizado na população empobrecida; 2) a nefasta flexibilização, aberta pela Leis e Diretrizes de Base da EducaçãoNacional (LDB) e iniciada no governo Fernando Henrique Cardoso em meados de 1990 (BRASIL, 1997) ${ }^{5}$. No governo Lula, esta flexibilização é consolidada com a isenção de fiscalização séria e rigorosa dos cursos e das instituições de ensino superior. O papel do Estado como agência reguladora (e não mais executora), resultante da

3 A este respeito ver o interessante artigo de Chaves (2010). A autora mostra as conseqüências da formação de oligopólios no ensino superior que se realiza por meio da fusão de organizações e negociação na bolsas de valores

4 Decreto que regulamenta a educação a distância (EaD) no Brasil abre a porta para esta modalidade de ensino (BRASIL, 2005). Pesquisas vêm mostrando que em uma década o número de alunos matriculados na modalidade ensino a distância (EAD) nos cursos de graduação, credenciados no Ministério da Educação (MEC), foi multiplicado em 158 vezes, passando de 5.287 matrículas, no ano 2000, para 838.125 estudantes em 2009, último número divulgado pelo Instituto Nacional de Estudos e Pesquisas Educacionais Anísio Teixeira (Inep).

${ }^{5}$ Com destaque para o Decreto 2.306/97 que cria os Centros Universitários (BRASIL, 1997).

Temporalis, Brasilia (DF), ano 11, n.21, p.239-270, jan./jun. 2011. 
contrarreforma do Estado brasileiro, tem servido à criação das bases jurídicas para a realização do modelo de ensino parametrizado pelas orientações do Banco Mundial.

Atualmente a flexibilização se mostra na ausência de controle e fiscalização do processo de expansão do ensino, na falta de fiscalização prévia ao processo de abertura de novos cursos e instituições ${ }^{6}$ e na ausência de aplicação de medidas punitivas em relação às instituições de qualidade duvidosa. Dentre as formas de flexibilização, a constituição de vários tipos de ensino superior obedece a lógica da fragmentação que separa as instituições de ensino que mantém o tripé ensino, pesquisa e extensão daquelas que apenas investem no ensino, sobretudo, no lucrativo. A exclusão da pesquisa nos espaços de formação profissional, que Marilena Chaui chamou de universidade operacional, representa a ausência de qualidade, mas também de controle sobre as instituições de ensino que podem se isentar da pesquisa e liberar as organizações e corporações que tenham interesse em investir num campo que não requer muitas exigências especificas. Este modelo de ensino rápido, ligeiro e barato, visa a atender as exigências do mercado de trabalho precarizado. Este quadro tem afetado profundamente a formação profissional dos assistentes sociais brasileiro, cuja perspectiva é formar profissionais capazes de fazer uma leitura critica da realidade e de nela se inserir criticamente. As entidades da categoria atentas a este retrocesso têm denunciado e tentado desvelar a lógica constitutiva deste processo de contrarreforma da educação superior brasileira e seus impactos na formação dos assistentes sociais:

\footnotetext{
${ }^{6}$ Os problemas que envolvem a avaliação a posteriori são complexos e não podem ser discutidos aqui.
} 


\section{temporolis}

GUERRA, Y. NA CONTRACORRENTE DA REFORMA

[...] a descoberta do curso de serviço social como nicho de valorização relaciona-se a uma demanda do mercado de trabalho, no formato que adquire o enfrentamento das expressões da questão social pelo Estado e as classes no neoliberalismo. Trata-se de produzir uma preparação para as requisições de mensuração e gestão/controle dos pobres. Nesse contexto não se requisita o perfil das diretrizes curriculares [...]. Ao contrário, o que se requisita é um profissional à imagem e semelhança da política social focalizada e minimalista de gestão da pobreza [...] (SOBRE..., 2010, p. 14).

Mas não são apenas os dados acima pontuados, por todos nós conhecidos, que mostram os ataques que a educação vem sofrendo e que nos habilitam a apreciar esta experiência. Como parte da mesma lógica de favorecimento dos interesses do capital contra os do trabalho, nos últimos anos, um número abusivo de escolas rurais têm sido fechadas. Este processo é objeto de denúncia pelo MST: de 2002 a 2009 foram fechadas mais de 24 mil escolas no campo, e enfrentado através da campanha Fechar Escola é Crime?.

Na contracorrente deste movimento de desmonte da educação pública de qualidade, o curso de graduação para assentados da reforma agrária, oferecido pela Escola de Serviço Social da Universidade Federal do Rio de Janeiro (UFRJ), promovido em parceria com o Instituto Nacional de Colonização e Reforma Agrária (INCRA), que é parte do Programa Nacional de Educação na Reforma Agrária (PRONERA), constitui-se numa iniciativa

7 O MST vem denunciando os interesses espúrios que orientam o fechamento de 24 mil escolas no campo entre os anos de 2002 e 2009. A luta contra a política neoliberal de fechamento de escolas e precariedade a que as escolas em atividade estão submeditas encontra-se na Campanha Fechar Escola é Crime, recentemente lançada pelo MST.

Temporalis, Brasilia (DF), ano 11, n.21, p.239-270, jan./jun. 2011. 
concreta de resistir a contrarreforma universitária em curso, como uma alternativa que, se não altera a ordem social imediata, porta a tendência de contrarresta-la.

Convidamos a todos a conhecer e acompanhar os primeiros passos desta iniciativa inédita e inovadora que se constitui numa maneira de enfrentar a tendência de uma educação pobre para pobres, na garantia do ensino público, gratuito, presencial, de qualidade e comprometido com os interesses da classe trabalhadora, intimamente conectada com a direção estratégica do projeto ético-político hegemônico do Serviço Social brasileiro e que porta um potencial de formar assistentes sociais comprometidos com um projeto de sociedade que vislumbra uma outra ordem social.

\section{A PROPOSTA - POR ERIVAN HILÁRIO ${ }^{8}$}

O PRONERA surge em um contexto de denúncia da situação educacional no campo brasileiro, naquele momento representada no fechamento das escolas, bem como o nível elevado do número de analfabetos no campo. Vale lembra que há nesse contexto uma intensificação do modelo de agricultura dominante no atual contexto histórico.

O PRONERA é uma expressão da luta dos trabalhadores/as organizados em seus movimentos sociais para garantir o saber elaborado e, por concomitante, lutando para quebrar o monopólio cultural em que está imbricado o conhecimento.

8 Licenciado em Pedagogia pela Universidade Federal do Rio Grande do Norte, Coordenador do Setor de Educação do Movimentos dos Trabalhadores Rurais sem Terra. 


\section{temporolis}

GUERRA, Y. NA CONTRACORRENTE DA REFORMA

Já está impregnado no imaginário social de que não aceitamos mais viver sem escola, a escolarização, ou seja, não aceitamos mais viver a margem da cultura elaborada (conhecimento) na sociedade.

A novidade no PRONERA é: a) entrada coletiva dos trabalhadores/as na universidade; b) a combinação do acesso ao conhecimento ligado com as questões da vida no campo, pensando assim na organização de dois tempos: escola e comunidade. Buscando aproximar o que tem sido tão distanciado: teoria e prática.

\section{a) Sobre o período de alternância}

Dois tempos que se alternam na tarefa de dar conta da totalidade das finalidades dos cursos. Não deve, portanto, haver demasiada valorização de um em detrimento do outro, ambos cumprem função específica, fazem parte de um todo articulado que é o curso. Para nós educadores em alguma medida tratamos o tempo comunidade como o momento do cumprimento de tarefa de casa (pensando em um sentido estrito da palavra), destinamos um monte de tarefas que não dialogam entre si, com isso, acabamos reforçando que o conhecimento é algo um tanto distante da vida, fragmentado.

Tempo Comunidade (TC) e Tempo Escola (TE) constituem-se uma forma de organização de trabalho pedagógico que integra o processo de escolarização de jovens e adultos do campo e foi construída com a finalidade de poder atender uma demanda objetiva que é trazer estudantes de distintos lugares (com o caso do curso de Serviço social) sem ter que desenraizá-los do seu trabalho, da sua cultura, do seu território e, principalmente, dos processos de inserção no movimento social do campo.

Temporalis, Brasilia (DF), ano 11, n.21, p.239-270, jan./jun. 2011. 
Com isso, o TC e TE diz respeito a um jeito específico de pensar os processos educativos do curso, trata-se de uma intencionalidade que tem em sua dinâmica tempos e espaços diferentes, com atividades direcionadas, articuladas pelos educadores, coordenação do curso, estudantes e seus respectivos movimentos sociais.

Portanto, pensar em um curso cujo pilar de organização pedagógica está ancorada na alternância desses dois tempos (TC e TC) requer necessariamente pensar em uma organização pedagógica-curricular por etapas e tempos e espaços educativos definidos.

O TE é desenvolvido predominantemente na instituição de ensino educacional de realização do curso, o TE é o tempo presencial. Já o TC é desenvolvido nos locais, territórios de origem dos estudantes.

\section{b) Sobre o Tempo Comunidade}

O curso não dá início e tão pouco encerra um processo de formação dos estudantes, trata-se de um processo formativo em um dado momento de suas vidas, quando estes chegam ao curso já tem uma caminhada (de vida, luta, etc), já tem experiência de participação e outros processos educativos (escolares e não escolares).

O seu território (local de origem) é tempo e espaço por excelência para seguir aprofundando o processo de apropriação do saber elaborado. A sua comunidade é referência (principal elemento da realidade) para o desenvolvimento de algumas atividades específicas como, por exemplo, a questão da pesquisa.

O TC e o TE é de exclusividade da instituição de ensino ou do Movimento Social? Podemos dizer de maneira geral que no TE a 


\section{tempordilis}

GUERRA, Y. NA CONTRACORRENTE DA REFORMA

Instituição educacional tem a centralidade (não exclusividade) do comando pedagógico e a organização social (o que inclui a comunidade) tem a centralidade (não exclusividade) do comando sobre o TC. Aqui não trata-se de uma dicotomia entre teoria e prática, ao contrário, ambos tempos são constituídos por excelência de teoria e prática social.

A organização ou planejamento do TC deve considerar a vida concreta dos estudantes que perpassa necessariamente pelas dimensões do trabalho, da cultura, da vida familiar, da vida em comunidade e da luta social.

O acompanhamento ao tempo comunidade é fundamental, faz necessário construir mecanismo para tal, de maneira em que possamos estabelecer um canal de comunicação mais direto com estes, o que vai desde a monitoria (o que envolve outros estudantes da pós-graduação da instituição educacional), até visitas em alguns desses territórios.

\section{O PRIMEIRO CURSO DE GRADUAÇÃO EM SERVIÇO SOCIAL - POR MARISTELA DALMORO ${ }^{9}$}

\subsection{Projeto de formação de uma turma especial de assentados da reforma agrária}

A turma especial de Serviço Social para assentados da reforma agrária, projeto implementado na Escola de Serviço Social (ESS) da Universidade Federal do Rio de Janeiro (UFRJ), é uma iniciativa dessa Escola em parceria com a Escola Nacional Florestan

\footnotetext{
${ }^{9}$ Docente da Escola de Serviço Social da UFJRJ e Coordenadora do Curso de Graduação em Serviço Social para os Assentados da Reforma Agrária.
}

Temporalis, Brasilia (DF), ano 11, n.21, p.239-270, jan./jun. 2011. 
Fernandes (ENFF) e o Movimento dos Trabalhadores Rurais Sem Terra (MST).

A ENFF nasce em 2005, por iniciativa dos movimentos sociais, especialmente o MST, e se propõe a ser um espaço de formação superior plural, nas mais diversas áreas do conhecimento não só para os militantes do MST, como também de outros movimentos sociais rurais e urbanos, do Brasil e de outros países da América Latina. Essa Escola oferece cursos de formação aos mais diversos segmentos de trabalhadores em todas as áreas do conhecimento, contando para isso, com professores voluntários de uma diversidade de Universidades tanto do Brasil como de outros países. A criação da ENFF ampliou a relação entre as universidades e os movimentos sociais e o acesso à educação de qualidade passou a fazer parte da agenda de luta dos movimentos sociais, principalmente do MST.

Tem papel fundamental nessa relação o PRONERA, vinculado ao INCRA. Esse programa, criado em 1998, e regulamentado através de decreto presidencial em 2010, é responsável pelo financiamento dos projetos de educação para trabalhadores beneficiários da reforma agrária, através de convênio com as universidades. Importante ressaltar que o PRONERA é uma política pública de educação do campo desenvolvida nas áreas de reforma agrária e é expressão de um amplo processo de organização e luta pela educação que inicia ainda na década de 1980. A sua elaboração e implementação, na década de 1990, ocorreu com a intensa participação de universidades públicas e dos movimentos sociais que com o propósito de enfrentar o analfabetismo no campo e romper com o monopólio cultural, propõe um modelo de educação democrático e coerente com as demandas dos trabalhadores do campo. Desde então, milhares de jovens e adultos, trabalhadores 


\section{temporolis}

GUERRA, Y. NA CONTRACORRENTE DA REFORMA

das áreas de Reforma Agrária têm garantido o direito de continuar os estudos em diferentes níveis de ensino. Segundo dados do INCRA, desde 1998, com a implantação do PRONERA, foram atendidos mais de 500 mil alunos, desde a alfabetização até a pósgraduação. No que se refere ao ensino superior, cerca de 48.700 jovens provenientes do meio agrário tiveram oportunidade de ingressar no ensino superior após a criação deste programa.

A turma especial de Serviço Social da ESS-UFRJ sintoniza-se com essa proposta e surge a partir da interlocução de segmentos do quadro docente da ESS com o MST e a ENFF. Essa parceria se consolida através da colaboração desses professores e estudantes da ESS em ações desenvolvidas pela ENFF, principalmente no que se refere aos cursos de formação. Essa parceria vem se fortalecendo consideravelmente, nos últimos anos, principalmente em função da afinidade político-ideológica de segmentos do quadro docente da ESS com os princípios da ENFF e MST. A criação dessa turma especial de Serviço Social é uma entre outras iniciativas que tem como objetivo contribuir com o fortalecimento da organização política dos trabalhadores e fortalecer, como isso, um projeto de esquerda e de radicalização democrática.

Pode-se mencionar dois projetos de extensão que contaram ou contam com uma ampla participação de professores e estudantes da ESS na sua elaboração e execução e que foram fundamentais no aprofundamento da relação da ESS com o MST e a ENFF. O primeiro, que tem início em 2004 é o curso de extensão de Teoria Social e Produção de Conhecimento, coordenado inicialmente pelo Centro de Ciências Humanas (CFCH/UFRJ), e, em 2007, pelo Núcleo de Estudo em Políticas Públicas em Direitos Humanos (NEPP-DH), órgão suplementar ao $\mathrm{CFCH}$. Esse curso, atualmente em sua terceira edição, tem grande participação de professores da ESS,

Temporalis, Brasilia (DF), ano 11, n.21, p.239-270, jan./jun. 2011. 
inclusive na coordenação, e de alunos, tanto da graduação como da pós-graduação, na condição de monitores.

Outra experiência relevante que teve início 2006 e que estreitou a relação da ESS com o MST, foi o projeto de estágio e extensão em áreas de acampamentos e assentamentos da reforma agrária, vinculadas ao MST. No decorrer de três anos de vigência desse projeto, em torno de 100 alunos do curso de Serviço Social realizaram estágio em áreas de reforma agrária. Fortaleceu-se o estudo e pesquisa em temáticas derivadas dessas experiências, principalmente no que se refere à questão agrária e movimentos sociais. Temos hoje, várias monografias defendidas sobre esses temas e um número significativo de estudantes da pós-graduação que tem como objeto de pesquisa a questão agrária e os movimentos sociais do campo. Isso, certamente, é um ganho da Escola e do próprio Serviço Social, pois amplia o leque de temas de investigação e aprofunda a relação com questões relativas ao mundo agrário e as lutas sociais do campo, muito distantes da profissão.

É no decorrer da execução desse projeto que se fortalece a demanda de militantes do MST do Rio de Janeiro e da ENFF para a criação dessa turma de Serviço Social de assentados da reforma agrária. O debate por parte de um segmento de professores da Escola de Serviço Social possibilitou o amadurecimento da proposta que culminou na elaboração do projeto de criação da turma especial de assentados da reforma agrária.

Após ter sido amplamente discutida pelo conjunto dos docentes da ESS, essa proposta foi aprovada pela Congregação da Escola e encaminhada para as demais instâncias da Universidade para ser avaliada. Os trâmites necessários para a sua aprovação na UFRJ e 


\section{tempordils}

GUERRA, Y. NA CONTRACORRENTE DA REFORMA

no INCRA estenderam-se de dezembro de 2009, até março de 2011, data de inicio do curso. Nesse período o processo tramitou em várias instâncias acadêmicas, jurídicas e administrativas da UFRJ e do INCRA nas quais foram avaliadas a sua relevância acadêmica bem como sua exeqüibilidade físico-financeira, condição necessária para o estabelecimento de um termo de cooperação entre essas duas instituições.

Vários obstáculos surgiram no decorrer desse processo, grande parte deles, relativos aos procedimentos burocrático-admistrativos e legais ou por questões de ordem pedagógica. Essas dificuldades foram sendo sanadas na medida em que surgiam, contando com o apoio de alguns técnicos e docentes responsáveis pelos setores adminstrativos e acadêmicos da UFRJ, alguns deles comprometidos com a sua implementação.

As dificuldades surgiam, na maioria das vezes, pelo ineditismo e ousadia dessa proposta. O seu vínculo orgânico com os movimentos sociais, mais especificamente com o MST expuseram algumas divergências de fundo político-ideológico que se não comprometeram o andamento do processo colocaram algumas entraves para a sua aprovação na Universidade. Convertidas em questões de ordem burocrático-adminstrativas ou acadêmicas, as divergências explicitaram concepções distintas do papel da universidade prevalecendo em algumas análises, uma visão elitista, disciplinadora e burocratizada dessa instituição. Tais divergências e confrontos no decorrer do processo deixaram claro que a universidade é um campo de disputa e que se expressam no seu interior, projetos societários distintos. A aprovação da proposta em questão seria uma estratégia, entre outras, que poderia ampliar a inserção dos setores populares na universidade fortalecendo, com isso, um projeto alternativo fundado na socialização do

Temporalis, Brasilia (DF), ano 11, n.21, p.239-270, jan./jun. 2011. 


\section{temporalis \\ GUERRA, Y. NA CONTRACORRENTE DA REFORMA}

conhecimento cientifico, condição fundamental para a democratização da própria sociedade.

O projeto de formação de uma turma especial de graduação para assentados da reforma agrária, proposta inovadora no interior da UFRJ, só foi possível pelo empenho de um grande número de professores e, principalmente da direção da ESS e pelo apoio dos profissionais vinculados ao INCRA/PRONERA, e dos coordenadores da Escola Florestan Fernandes. Importante ressaltar a adesão a esse projeto de um significativo número de docentes e discentes das várias unidades de ensino da UFRJ e, em especial, os educadores vinculados ao Centro de Ciências Humanas (CFCH), a reitoria que deu suporte financeiro e político-acadêmico a essa proposta.

Esse processo culminou na assinatura do Termo de Cooperação entre UFRJ e INCRA, em dezembro de 2010, exigência necessária para a implementação da proposta na Escola de Serviço Social. A seleção dos alunos se deu através de um concurso especial, realizado no mês de fevereiro o que garantiu que o início das aulas ocorresse no mês de março de 2011.

Ingressam na Escola de Serviço Social, através desse processo, 60 trabalhadores rurais, vinculados a acampamentos e assentamentos da reforma agrária e localizados em dezenove estados do Brasil. É importante frisar que essa turma se constitui na sua maioria de militantes basicamente do MST, mas estão também representados, a Via Campesina, o Movimento de Mulheres do Campo e o Movimento de Pequenos Agricultores (MPA). Precede a isso a sua condição de acampado ou assentado em projetos de reforma agrária, critério indispensável para ser reconhecido como beneficiário do PRONERA, por parte do INCRA. A constituição 


\section{tempordils}

GUERRA, Y. NA CONTRACORRENTE DA REFORMA

dessa turma de estudantes de Serviço Social, portanto, se adequou a esse critério e a seleção se restringiu ao público beneficiário dos projetos de reforma agrária. Vale ressaltar a heterogeneidade dessa turma a começar pela faixa etária, pois temos alunos na faixa de 17 anos até 50 anos. Outro fator importante é a trajetória desses trabalhadores. Se alguns estão iniciando na militância, temos outros que já acumulam uma longa experiência, muitos deles assumindo a função de dirigente político dos movimentos sociais.

A grande novidade nessa proposta e a qual a Escola de Serviço Social precisou se adequar é a forma de organização do curso, que tem como referencia a Pedagogia da Alternância que consiste em uma metodologia de organização do ensino constituída por dois tempos educativos: Tempo Escola e Tempo Comunidade. Tem como referência a experiência realizada na França nos primeiros anos do século XX conhecida como Pedagogia da Alternância, no qual se alternava o tempo em que os jovens permaneciam na escola e o tempo em que ficavam em suas comunidades. A idéia básica era conciliar o estudo e o trabalho na lavoura da família. Pode-se dizer que essa metodologia procura combinar, no processo de formação do jovem agricultor, períodos de vivência na escola com tempos transcorridos no meio familiar. Alterna-se, assim, a formação agrícola na propriedade com a formação teórica geral na escola que, além das disciplinas básicas, engloba uma preparação para a vida associativa e comunitária.

Esse método chega ao Brasil nos anos de 1960 e é utilizado, na organização do ensino, principalmente nas Escolas Família Rural, projetos implementados e financiados pela Igreja Católica. Atualmente existem várias experiências de educação que utilizam a Pedagogia da Alternância como método e essa pode ser considerada como uma referência para a consolidação dos

Temporalis, Brasilia (DF), ano 11, n.21, p.239-270, jan./jun. 2011. 
projetos do PRONERA em parceria com o MST e Escola Florestan Fernandes, entre os quais está turma especial de Serviço Social. Essa estratégia que foi sendo construída e reconstruída no decorrer dos últimos anos tem como principio básico garantir aos trabalhadores do campo, beneficiários da reforma agrária, a elevação do nível cultural rompendo, dessa forma, com um ciclo bastante perverso de supremacia dos valores urbanos e de negação do protagonismo dos trabalhadores do campo.

Por constituir-se por dois tempos educativos: o Tempo Escola e o Tempo Comunidade, essa metodologia contribui para a permanência dos trabalhadores na universidade e, ao mesmo tempo permite que continuem suas atividades em seus acampamentos e assentamentos onde residem. No projeto do curso de Serviço Social, os estudantes permanecem no Rio de Janeiro dois meses, período em que cursam as disciplinas e participam de outras atividades tanto acadêmicas como políticas. No tempo que permanecem na universidade, têm cobertura do PRONERA e da Universidade no que se refere à hospedagem, alimentação, transporte e material didático. Findo esse tempo, retornam as suas comunidades para desenvolver tarefas que consolidem a prática a partir do conhecimento adquirido nas aulas. Podem, com isso, combinar o tempo que devem estar nos assentamentos e nas suas comunidades, trabalhando, e o tempo que devem dedicar aos estudos, na universidade.

A constituição de cursos para trabalhadores do campo pautados por essa metodologia possibilita que ingressem na universidade sem sofrer um processo de desenraizamento, muito presentes nos processos educativos tradicionais. Nessa relação entre dois tempos educativos distintos, os estudantes estreitam o contato com o seu cotidiano de trabalho e militância o que assegura o fortalecimento 


\section{tempordils}

GUERRA, Y. NA CONTRACORRENTE DA REFORMA

dos vínculos com essa realidade e, ao mesmo tempo, os aproxima do conhecimento acadêmico. Estabelece-se, com isso, uma proximidade entre as experiências de vida, trabalho e militância e o ambiente acadêmico, contribuindo, portanto, para a diminuição da dicotomia entre teoria e prática. No tempo da universidade realizase a reflexão, problematização e aprofundamento do conhecimento, e o tempo comunidade destina-se aos estudos e pesquisas articulando esses conhecimentos com a realidade. Nessa relação dialética entre espaços e tempos diferentes vão sendo construídos novos conhecimentos, que contribuirão com o processo de formação dos estudantes trabalhadores, mas também, poderão oferecer novos subsídios ao debate do Serviço Social e a universidade.

A criação dessa turma especial de assentados da reforma agrária, ao mesmo tempo em que se afina à função social da universidade de democratizar o acesso à educação tem como principio garantir e esses estudantes ensino de qualidade resguardando os princípios que orientam o projeto de formação profissional do Serviço Social e os propósitos da Escola Florestan Fernandes que é garantir aos trabalhadores do campo acesso ao saber cientifico que confrontado ao conhecimento acumulado em suas experiências de vida, trabalho e militância, possam construir-se como sujeito coletivo. Ao mesmo tempo, é importante tratá-lo inserido na dinâmica que é hoje a universidade brasileira. Experiências como estas andam na contramão do movimento de privatização do ensino superior e das universidades públicas. Em um tempo de ampliação sem medida do ensino privado e dos cursos à distância, a constituição dessa turma de trabalhadores do campo soa de forma dissonante e será um grande desafio para o Serviço Social.

Temporalis, Brasilia (DF), ano 11, n.21, p.239-270, jan./jun. 2011. 
Certamente que essa iniciativa terá grande impacto no âmbito do Serviço Social brasileiro, pois vem para fortalecer os princípios que sustentam o projeto ético-político aproxima a profissão das demandas dos trabalhadores do campo e dos movimentos sociais. Aprofunda a relação da categoria profissional de importantes forças de esquerda, principalmente da ENFF e do MST que defendem que a educação deve contribuir para a transformação da sociedade atual, para a construção de uma nova ordem social baseada nos pilares da justiça social, da radicalidade democrática e nos valores humanistas e socialistas.

Esse projeto e os outros que virão, incidirão diretamente nos rumos do Serviço Social e fortalecerão a luta coletiva, a defesa da coisa pública, a revalorização da militância, tanto nos espaços das entidades da categoria, como nas lutas mais gerais, nas quais os assistentes sociais historicamente tem se envolvido.

\section{A PROPOSTA NA VISÃO DOS DOCENTES}

De fundamental importância são as reflexões do Prof. Rogério Lustosa Bastos ${ }^{10}$, que ministrou a Disciplina Introdução ao Trabalho Cientifico para a turma que trazemos a seguir:

A ciência existe apenas para servir aos negócios ou "para", de acordo com Brecht, "combater realmente as misérias humanas" nesta Globarbarização?

Esses eram os meus pensamentos quando adentrei, em uma tarde, na sala dos alunos do MST, do primeiro período do curso de graduação em Serviço Social da UFRJ. Depois dos cumprimentos de praxe, mal comecei a lhes apresentar o conceito de ciência, endereçam-me

10 Professor Associado da Escola de Serviço Social da UFRJ. 


\section{temporolis}

GUERRA, Y. NA CONTRACORRENTE DA REFORMA

a primeira pergunta: - Professor, por favor, o que o senhor quer dizer com 'subjacente'?

Aproveitando aquela pergunta que também indicava que talvez eu não estivesse usando a palavra adequadamente, redefini a ciência pela frase já citada acima de Brecht, quer dizer, escrevi essa frase no quadro e pedi para que eles me falassem o que estava por detrás daquela expressão: "Não se faz ciência sem interesse", disse-me um senhor; "não se faz ciência sem sentido político", argumentou uma jovem com um violão na mão; "não se faz ciência sem procurarmos nossa turma", falou um dos líderes dali cujo rosto compunha com um par de óculos de lentes fortes. Sim! Expliquei-Ihes que ali estava o dito 'subjacente', o "não dito" do ato científico. Tal fato era importante, mas o 'espírito da coisa' ali era cada um indagar: "A serviço de quem vamos colocar a ciência?".

Afora usar o método Paulo Freire em minhas aulas sobre "introdução ao Trabalho Científico", as quais visam principalmente que o aluno aprenda a fazer um anteprojeto de pesquisa ${ }^{11}$, para alcançar tal objetivo $e$ tentar passar o conteúdo, sempre que possível, usamos de alguma linguagem artística (teatro, literatura, etc.). Assim, o fizemos com a turma do MST.

Um ponto importante, para mim, ao ministrar essa disciplina para o MST, foi uma reunião que fazíamos de avaliação, praticamente toda semana: refiro-me a que acontecia com toda equipe de docentes envolvida, mais a coordenadora do curso, representantes do MST (eles faziam rodízio semanal) e os monitores. Ali não só pensávamos sobre o que estávamos fazendo, mas

11 Para ministrar tal disciplina, adotou-se o livro: BASTOS (2009).

Temporalis, Brasilia (DF), ano 11, n.21, p.239-270, jan./jun. 2011. 
também procurávamos tirar o que poderia ser mais relevante para o curso em questão. Posso dizer que uma das grandes lições que aprendi nessas reuniões foi que uma boa aula caminha mais para um "concerto" (no qual se considera a equipe, mas também não se anula a singularidade do ato de ensinar e de aprender), e menos para um "sermão".

$[\cdots]$

Marx aderiu à luta da classe trabalhadora não de forma 'fria'(apenas pelo lado racional), mas sim pela paixão em prol da mudança que esse grupo passava para ele. Ao ter um dos primeiros contatos por ali, viu que se fosse possível escrever uma das frases mais belas sobre a fraternidade, bastava olhar para fisionomia de cada um daqueles trabalhadores que se estaria diante dela [(KONDER, 2007)]. No último dia de aula, ao fazermos uma avaliação sobre o curso, além de a turma ter sido generosa com o professor, ela me apresentou muitas questões sérias, as quais, muitas delas, além de terem me ensinado bastante, ficaram em aberto. Dentre elas, destaco duas: $1^{a}$ - "Professor, tudo bem que seja importante aprender a linguagem da ciência (a linguagem dos dominantes, inclusive para não nos deixarmos explorar por eles), mas não seria possível se criar uma ciência revolucionária?" $2^{a}$ - "Isto não poderia se dar, sobretudo, a partir das questões colocadas pelo próprio trabalhador, a partir do campo?".

Outro depoimento da maior importância é o do prof. Henrique Wellen $^{12}$ da disciplina Teoria Política a qual trazemos a seguir:

A importância do curso de Serviço Social da UFRJ destinado aos assentados da Reforma Agrária pode ser

12 Professor Adjunto da Escola de Serviço Social da UFRJ. 
auferida a partir de quatro parâmetros centrais. Em primeiro lugar, em relação aos discentes, trata-se não somente de uma ampliação quantitativa do acesso ao conhecimento e à formação profissional, mas, também, que esse acesso acontece para pessoas que foram historicamente excluídas e marginalizadas da formação acadêmica. Contribuir para a formação desses alunos não é apenas um aumento nas vagas para a universidade, mas também a possibilidade de acesso para um público relegado pela academia. Em segundo lugar, representa uma experiência expressiva para a formação dos próprios professores que, além de contar com uma turma bastante comprometida com a formação teórica e prática, necessita cotidianamente testar o conteúdo das aulas a partir de mediações concretas da realidade social. Para dar respostas à altura dessa sede e desse tipo de conhecimento, o professor é impulsionado a pensar e repensar seu acúmulo teórico a partir de uma base materialista: a teoria como uma expressão e uma explicação do que acontece na realidade. Em terceiro lugar, essa iniciativa leva à reflexão sobre o papel e a função da própria universidade, servindo para criticar sua postura correntemente elitista, e abrindo o debate para um marco democrático. Quando esse mundo real, muitas vezes rejeitado pela universidade, de alunos, com falas e comportamentos oriundos da classe trabalhadora, aparece no cotidiano da academia, promovem-se questionamentos e mudanças no seio dessa entidade. Desde a organização do movimento estudantil, que absorve demandas mais concretas e universais, até as atividades culturais ofertadas pela universidade, tudo isso é mencionado pelo parâmetro concreto dos lutadores sociais. Por último, e de central importância, a criação, a manutenção e a ampliação dessa experiência significa uma conquista para a classe trabalhadora na sua luta pela socialização econômica, política e cultural. Seguindo o lema desses alunos $e$ militantes, trata-se não somente de ocupar um espaço

Temporalis, Brasilia (DF), ano 11, n.21, p.239-270, jan./jun. 2011. 
relegado historicamente para poucos, mas de resistir nessa luta e de produzir novas conquistas. Ainda que de forma singela, a criação de cursos como esse serve para romper padrões culturais e círculos de poder, forçando - caminho para a educação pública, gratuita, de qualidade, e baseada na perspectiva da classe trabalhadora. Não é apenas uma luta pela ampliação do acesso à educação hegemônica, mas da construção de outro tipo de educação. De uma educação crítica e questionadora. Esse curso não é, portanto, um favor que a sociedade fornece aos fracos e oprimidos, mas é uma conquista histórica dos trabalhadores que lutaram e morreram pelo ideal de uma sociedade emancipada. Que a luta continue bravamente e que o curso dos assentados não apenas continue resistindo, mas que seja uma semente revolucionária.

\section{OS ESTUDANTES}

\section{Elaine Cristina Locan - Guararema}

O curso de serviço social na UFRJ nos propicia fazermos um leitura de mundo partindo de uma perspectiva teórico crítica. Analisando a chamada questão social, e reafirmando o que disse o professor José Paulo Netto ${ }^{13}$, a pauperização não é passível de solução dentro do modelo capitalista, por isso, a solução passa necessariamente por uma ruptura deste sistema. Por isso, é de extrema importância o acesso ao conhecimento cientifico, que propicie-nos 0 conhecimento da nossa história, utilizando um método que "desvele" o que está escondido atrás das aparências, isto é, mostre as verdadeiras contradições que precisam ser superadas.

13 Por ocasião da aula inaugural deste Curso. 


\section{temporolis}

GUERRA, Y. NA CONTRACORRENTE DA REFORMA

Acredito que estudar serviço social, contribuirá para o avanço de cada militante que está estudando, na apropriação e elaboração do conhecimento cientifico, com princípios e valores que colaborem na construção de um projeto político estratégico, com a organização da classe trabalhadora, para enfrentar e romper com o imperialismo em prol de uma nova sociedade.

\section{Jose Maria Tardin - Martinópolis (SP)}

Uma turma de Sem Terra na UFRJ, uma Universidade Federal, pública, é a comprovação material da marcha emancipatória que os Movimentos Camponeses realizam neste país oligarca-burguês, retrógrada, conservadora, racista, submissa a burguesia imperialista. É mais uma vitória contra o latifúndio da terra e do conhecimento sistematizado-formal. É ampliar a grandeza da nossa utopia. Eu cheguei aqui aos meus 49 anos. Me sinto um menino que segue empunhando a Bandeira Vermelha!

\section{Adriano Ribeiro dos Santos - Acampamento Antonio Conselheiro (MT)}

Para mim fazer este curso é de grande importância, porque eu posso conhecer melhor como funciona a questão social no Brasil e a partir disso poder intervir na realidade e poder ajudar melhor a classe onde a gente vive. Também é uma oportunidade de estudo em um escola de grande qualidade e a Escola de Serviço social da UFRJ.

\section{Marlon Fabiano Ruppenthal - Marechal Candido Rondom (PR)}

Este curso vem para contribuir na luta por mudanças estruturais e sociais para o campo Brasileiro em 
especial as áreas ligadas ao Movimento dos trabalhadores Rurais Sem Terra, buscando formar militantes dos vários setores e atividades ligadas ao movimento, bem como trazer presente o papel deste profissional no processo histórico ao qual surgiu, e as mudanças que ocorreram e onde este se insere. Vem trazer este profissional para a luta da classe trabalhadora, buscando uma ação coletiva e não individualizada dos problemas sociais brasileiros, busca discutir a causa e não tratar os efeitos da exploração da classe trabalhadora, onde resolvem os problemas com uma bolsa família, ou programas focalizados, bem como programas que vem a excluir a população pobre, levando-os para as periferias das cidades e enriquecer as empresas privadas, com "Minha casa minha Dilma" como contam em tom de piada nos butecos da vida.

Reforça também os nossos princípios, enquanto movimento, que é o estudo, pois são militantes que passaram por cursos, e terminaram o seu segundo grau, tendo conquistado este espaço para continuarem a sua formação em uma das melhores faculdades do Brasil, se antes não tinha espaço para o camponês em uma faculdade, devemos refletir sobre camponeses sem terra no ano de 2011 ocupam o latifúndio do saber, $e$ não se contentam em apenas se formar como profissionais em serviço social, mas querem discutir o papel deste na construção de um país melhor para toda a Trabalhadora.

Também nos dá um novo espaço de luta, pois agora somos universitários, e dentro desta instituição também há lutas, e posições diferentes, poderemos nos somar ao movimento estudantil e tentar evitar as privatizações dos espaços públicos que vem sendo o interesse do capital.

Enquanto pessoa busco a formação política ideológica, e fico feliz em ver os educadores que estamos tendo a 


\section{temporalis}

GUERRA, Y. NA CONTRACORRENTE DA REFORMA

oportunidade de ter neste espaço. Como disse José Paulo Neto na abertura do curso "Estes Sem Terra deverão ser os melhores Alunos da faculdade e serão", independentemente das atividades que temos que desenvolver em nosso dia a dia, buscarei o máximo possível do conhecimento que nos foi negado.

\section{Claudia Monica dos Santos - Presidente da Associação Brasileira de Ensino e Pesquisa em Serviço Social (ABEPSS)}

Hoje, está em andamento no Brasil um projeto de reordenamento do papel da educação superior. Esse objetivo vem sendo materializado através da proposta da Universidade Nova, do Programa de Apoio ao Plano de Reestruturação e Expansão das Universidades Federais (REUNI - 24/04/2007) e da proposta de Universidade Aberta (Decreto n. 5.622 de 19/12/2005).

O governo federal lançou, em 24 de abril de 2007, o Plano de Desenvolvimento da Educação (PDE) (constitutivo do Programa de Aceleramento do Crescimento (PAC)). O PDE é constituído por um conjunto de decretos, projetos de lei, resoluções $e$ portarias, dando continuidade à reforma universitária já em andamento.Trata-se de uma política que visa atender a uma forte demanda social por formação superior, sem a qualidade requerida para tal e com poucas possibilidades de inclusão dos jovens oriundos da classe trabalhadora na real profissionalização de nível universitário.lgualmente grave é a expansão do Ensino a Distância (EaD), que, juntamente, com o processo de privatização e mercantilização do ensino superior, fazem ampliar, exageradamente e sem critérios, o número de cursos privados no Brasil, principalmente, na região sudeste. A Turma especial de Serviço Social para assentados da reforma agrária, em desenvolvimento na Escola de Serviço Social, da Universidade Federal do Rio de Janeiro, é um exemplo

Temporalis, Brasilia (DF), ano 11, n.21, p.239-270, jan./jun. 2011. 
de como podemos democratizar o acesso ao ensino superior no país, sem, entretanto, mercantilizar $e$ deteriorar o processo de formação profissional defendido pela categoria, ou seja, resguardando um ensino público, gratuito, presencial, laico, socialmente referenciado e com qualidade.

Conforme o depoimento da coordenadora do curso, Maristela Dalmoro, o curso tem como referência a metodologia da "Pedagogia da Alternância" que consiste em uma organização do ensino constituída por dois tempos educativos: Tempo Escola e Tempo Comunidade. Entendemos que essa metodologia, ao garantir a concepção de "educação" contida em nosso projeto de formação profissional - como prática social, portanto, requer interação entre sujeitos e destes com a sociedade, requer preparar para a vida em sociedade $e$ promover saberes socialmente referenciados garantem os princípios e diretrizes do mesmo, quais sejam: flexibilidade dos currículos; rigoroso trato teórico, histórico e metodológico da realidade social e do próprio Serviço Social; a superação da fragmentação dos conteúdos; o estabelecimento das dimensões investigativa e interventiva como condição central da formação e a relação teoria e realidade; padrões iguais entre os cursos quanto à qualidade e desempenho; Caráter interdisciplinar nas várias dimensões do projeto de formação profissional; indissociabilidade do ensino, pesquisa e extensão; exercício do pluralismo; a ética como um princípio formativo perpassando a formação curricular; $a$ indissociabilidade entre estágio $e$ supervisão acadêmica.

Defendemos a democratização do acesso ao ensino superior no país, sem discriminação da população menos favorecida. Desejamos que todos tenham o mesmo nível de educação! 


\section{temporolis}

GUERRA, Y. NA CONTRACORRENTE DA REFORMA

\section{CONSIDERAÇÕES FINAIS}

Como forma de enfrentar a precarização problematizada acima, um novo modelo de formação profissional tem se gestado. Ele mostra que é possível conjugar expansão com qualidade. Ele é a prova de que é possível a ampliação de novas vagas, inserção de novos sujeitos sociais até então alijados do acesso ao conhecimento formal, garantindo os principio de um ensino presencial, publico, gratuito, de qualidade e socialmente relevante. Mostra ainda que o direcionamento de recursos públicos para iniciativas como esta não é produto do "favor", mas resultado da luta de classe, do que depende o nível e grau de organização e mobilização da classe trabalhadora.

Finalizando este relato, uma última consideração se faz necessária: para nós assistentes sociais que estamos na carreira docentes, este curso, ademais de todas as razões acima, constitui-se num desafio e numa grande possibilidade. O desafio, como nos ensina Marx, é o de que para esta proposta, pelo seu caráter inovador, o educador tem que ser educado. E ai entra a concepção de educação enquanto formação do homem em toda a sua plenitude e humanidade, na busca da vida plena de sentidos, que passa pela relação intrínseca entre educação e formação política visando a que os estudantes, futuros assistentes sociais, possam desenvolver sua consciência crítica e transcender valores egoístas, individualistas, narcísicos, movimento indispensável à construção do novo homem.

O investimento na formação de sujeitos sociais que vivenciem valores sóciocêntricos, que reconheçam seus vínculos com o gênero humano e que não perderam a capacidade de se indignarem diante da miséria, da exploração, da opressão, da

Temporalis, Brasilia (DF), ano 11, n.21, p.239-270, jan./jun. 2011. 
discriminação, do preconceito. A formação de uma intelectualidade militante constitui-se num desafio e numa nova possibilidade para a profissão, na medida em que se choca com o perfil hegemônico dos estudantes de Serviço Social na atualidade. O desafio está, ainda, em revelar o significado desta profissão no contexto da sociedade burguesa, de desvelar a contradição que está na base da sua própria existência e questionar a mística da ajuda retratada na imagem social da profissão, pondo a luz a sua necessária dimensão política, que não se confunde com militância. Mas, apesar dos desafios, vejo enormes possibilidades já que a profissão e os movimentos sociais partilham da mesma perspectiva de romper com esta ordem social e construir uma outra sociedade, para além do capital. Nesta direção, para garantir o conhecimento como instrumentos de emancipação social, a universidade deve se engajar em várias frentes de luta. Eis ai uma nova trincheira de luta para os que virão [...]

Não tenho o sol escondido no meu bolso de palavras. Sou simplesmente um homem

para quem já a primeira e desolada pessoa do singular - foi deixando, devagar, sofridamente de ser, para transformar-se - muito mais sofridamente na primeira e profunda pessoa do plural.

Não importa que doa: é tempo de avançar de mão dada com quem vai no mesmo rumo, mesmo que longe ainda esteja 


\section{temporalis}

GUERRA, Y. NA CONTRACORRENTE DA REFORMA

de aprender a conjugar

o verbo amar.

É tempo sobretudo

de deixar de ser apenas

a solitária vanguarda

de nós mesmos.

Se trata de ir ao encontro.

(Dura no peito, arde a límpida

verdade dos nossos erros)

Se trata de abrir o rumo

Os que virão, serão povo,

e saber serão, lutando.

(Para os que virão - Thiago de Mello)

\section{REFERÊNCIAS}

BASTOS, Rogério Lustosa. Ciências humanas e complexidades: métodos e técnicas de pesquisa: o caos e a nova ciência. Rio de Janeiro: E-papers, 2009.

CHAVES, Vera Lúcia Jacob. Expansão da privatização/mercantilização do ensino superior brasileiro: a formação dos oligopólios. Educ. Soc., Campinas, v.31, n.11, p.481500, abr./jun. 2010. Disponível em: <http://www.scielo.br/pdf/es/v31n111/v31n111a10.pdf>.

BRASIL. Decreto $n^{\circ}$ 5.622, de 19 de dezembro de 2005. Regulamenta o art. 80 da Lei $n^{\circ}$ 9.394, de 20 de dezembro de 1996, que estabelece as diretrizes e bases da educação nacional. Disponível em: https:// <www.planalto.gov.br/ccivil_03/_Ato20042006/2005/Decreto/D5622.htm>.

Temporalis, Brasilia (DF), ano 11, n.21, p.239-270, jan./jun. 2011. 


\section{tempordils}

GUERRA, Y. NA CONTRACORRENTE DA REFORMA

BRASIL. Decreto n².306, de 19 de agosto de 1997. Regulamenta, para o Sistema Federal de Ensino, as disposições contidas no art. 10 da Medida Provisória n 1.477-39, de 8 de agosto de 1997, e nos arts. $16,19,20,45,46$ e $\S 1^{\circ}, 52$, parágrafo único, 54 e 88 da Lei $n^{\circ}$ 9.394, de 20 de dezembro de 1996, e dá outras providências. Revogado pelo Decreto $\mathrm{n}^{\circ} 3.860$, de 9 de julho de 2001. Disponível em: <http://www.planalto.gov.br/ccivil_03/decreto/D2306.htm>.

KONDER, Leandro. Marx; os revolucionários também amam. In: . Sobre o amor. São Paulo: Boitempo, 2007.

SOBRE a incompatibilidade entre a graduação a distancia e o Serviço Social. [Brasília]: CFESS/CRESS/ABEPSS/ENESSO, 2010. Disponível em:

<http://www.abepss.org.br/briefing/documentos/DocumentoIncompatibilidade-entre-Graduacao-Distancia-ServicoSocial.pdf>.

270 Temporalis, Brasilia (DF), ano 11, n.21, p.239-270, jan./jun. 2011. 